\title{
Suicide Ideation Associations with Attitudes toward Suicide, Quality of Life, and Attitudes toward Death and Dying among Chinese, Korean, Thai, and Vietnamese High School Seniors
}

\author{
Noy S. Kay ${ }^{1}$, Sudgasame Jantaraweragul ${ }^{1,2}$, Vijit Kanungsukkasem ${ }^{3}$, Kaigang $\mathrm{Li}^{4}$, \\ Megan R. Jones ${ }^{1} \&$ Yan Huang ${ }^{1}$ \\ ${ }^{1}$ School of Public Health, Physical Education and Recreation, Indiana University, Bloomington, USA \\ ${ }^{2}$ IvyTech Community College, Bloomington, USA \\ ${ }^{3}$ Faculty of Sport Science, Chulalongkorn University, Bangkok, Thailand \\ ${ }^{4}$ National Institution of Child Health and Human Development, Bethesda, Maryland \\ Correspondence: Noy S. Kay, School of Public Health, Physical Education and Recreation, Indiana University, \\ Bloomington, IN, 47405, USA. Tel: 1-812-855-2156. E-mail: noyskay@indiana.edu
}

Received: June 27, 2012

doi:10.5539/jel.v1n2p192

Accepted: September 6, 2012

Online Published: October 15, 2012

URL: http://dx.doi.org/10.5539/jel.v1n2p192

\begin{abstract}
Suicide of an individual could leave devastating consequences for family, friends, relatives, and society. Suicide could be considered a serious concern and issue to public health, especially among adolescents. The purpose of the study was to examine associations of suicide ideation with attitudes toward suicide (ATS), quality of life (QOL), and attitudes toward death and dying (ADD) in high school seniors. The participants were conveniently sampled and consisted of 1,247 high school senior students from China, South Korea, Thailand, and Vietnam. The survey found that $21.7 \%$ of the Chinese, $20.9 \%$ of the Korean, $16.8 \%$ of the Thai, and $26.3 \%$ of the Vietnamese participants exhibited suicide ideation. The analysis revealed that student suicide ideation was significantly associated with ATS, QOL, and sustained elements of depression during the past 12 months in all four countries. In addition, there were statistically differences among the Chinese, Korean, Thai, and Vietnamese students in QOL, ATS, and ADD. The analysis determined that there were certain predictive factors for suicide ideation in the participants. The impact of these findings could extend to professional roles within the school system including curricula and services. Administrators, faculty, or social workers could gain a better understanding of the current suicide ideation phenomenon and help raise awareness to reduce potential suicide attempts among high school students in these Asian countries.
\end{abstract}

Keywords: Asian high school student, adolescent suicide behavior, high school suicide, hopeless feeling, pacific rim country, suicide attempt, prolonged sadness

\section{Introduction}

There are an estimated 10 to 20 million non-fatal attempted suicides every year worldwide (Bertolote and Fleischmann, 2002). The World Health Organization (WHO) estimates that 873,000 people in the world die by suicide each year (WHO, 2006). Suicide is defined as the deliberate self-destruction of a human being, by causing the body to cease functioning (Hawton and Heeringen, 2009). Suicide appears in almost all societies and it is a leading cause of death among teenagers and adults under 35 years of age ( $\mathrm{O}^{\prime}$ Connor and Sheehy, 2009).

The United States Federal Statistics reported that suicide is the third leading cause of death for adolescents and young people, age 15 to 19 (Pirruccello, 2010). It remains a serious public health problem in communities throughout America. In the United States, the term "suicide ideation" was used by the Center for Disease Control and Prevention (CDC) emphasized that it is a "collective continuum from thinking about ending one's own life, to developing a plan, to a non-fatal suicide attempt, and to ending one's life" (CDC, 2011). In the year 2010, the CDC asked for a consistent conceptual theoretical framework to bridge with an operational practical model so that "researchers can measure and monitor the incidence of suicide and predicting factor trends over time in a uniform standard" (CDC, 2011). In addition, the model would help determine the magnitude of suicide and compare the problem across jurisdictions (CDC, 2011). Within numerous studies on suicide and suicide behavior, 
the concept of suicide ideation is not adequately addressed, thus not bridging with the CDC's operational definition.

Andress addressed suicide ideation by stating that there are three phases in suicide commitment including: the resolution phase, the initiation phase, and the postponement phase (Andress, 1996). Safsten added to Andress's model by illustrating the suicidal differences between age groups (Safsten, 2004). Among the elderly, suicide is exhibited through silent suicide attempts by means of starvation or medical non-compliance (Safsten, 2004). This differs from the adolescent or young adult age group of violent activities. The behavior leading to obstructive actions can be observed into begging attention by youngster through suicidal gestures (Safsten, 2004).

The available records suggested that Asian countries account for approximately $60 \%$ of all suicides worldwide (Wei and Chua, 2008). Together, China, India, and Japan account for more than $40 \%$ of all suicides across the globe (WHO, 2006). In the last two decades, suicide rates have increased in a number of Asian countries. South Korea saw an increase in suicide rates from 10.6 per 100,000 in 1995 to 23.8 per 100,000 in 2004 (Park and Lester, 2006). Hong Kong has witnessed an increase in suicides in the past 10 years, increasing from 11.8 per 100,000 in 1995 to 18.6 per 100,000 in 2004 (Wei and Chua, 2008). In 2002, the suicide rate in China was as high as 20.8 per 100,000 (WHO, 2007).

In China, a recent study suggested that there is an increasing public and policy concern about the issue of adolescent suicide attempts (Xing et al., 2010). A study of students in Hong Kong revealed that $7.3 \%$ of boys and $7.2 \%$ of girls in their high school years had attempted suicide, observed during a 12-month period (Yip et al., 2004). A study of Bangkok, Thailand youth reported an attempted suicide prevalence of $6.1 \%$ among students and girls were more likely than boys to attempt suicide (Ruangkanchanasetr, Plitponkarnpim, Hetrakul, and Kongsakon, 2005).

A study conducted with Western adolescents showed risk factors associated with suicide such as hopelessness, loneliness, and cognitive, psychological, social, and family factors (Page et al., 2006). However, studies focused on suicide by relating to quality of life (QOL), attitude toward suicide (ATS), and attitude toward death and dying (ADD) among Asian adolescents were not available. Cited studies had focused on suicide as the outcome rather than the question to signify the cause in the relationship.

A previous study by Kay and associates assessed the current status of suicide behavior and examined the association between suicidal behavior and components of the QOL among college students of China, Thailand, and Korea (Kay, Li, Xiao, Nokkaew, and Park, 2009). The study results found that 3.7\% Thai, $10 \%$ Chinese, and $13.2 \%$ Korean students exhibited suicidal behavior and were significantly associated with hopeless feelings among Chinese, Thai, and Korean students (Kay, et al., 2009). Also, all components were significantly associated with suicidal behavior among Chinese, Thai, and Korean students except the psychological domain among Thai students (Kay, et al., 2009). High school seniors and college students are closely related in age; however, the condition of their expectations and social skills could take on different roles in relation to their decision-making.

This present study has introduced additional factors to examine relationships between suicide ideation and QOL, ATS, and ADD in adolescents. This convenience sampling survey will be limited to Chinese, Korean, Thai, and Vietnamese senior high school students. This study will make an attempt to uncover, acknowledge, recognize, and predict the matter of suicide in adolescents among the selected Asian countries. In this study, the component of suicide ideation, as the operational definition framework, consists of three consequential stages including suicide thought (accumulating of sadness or depression), suicide planning or behavior (attention-seeking behavior), and suicide attempt (actually committing suicide).

The three main focuses of this study were: (1) to compare among the four countries of suicide thought based on the condition of accumulated or sustained sadness feelings, ATS, ADD, and QOL; (2) to determine the correlation among ATS, ADD, and QOL with suicidal thought, suicidal behavior, and suicide attempt; and (3) to examine the associations of predictive suicide ideation with ATS, ADD and QOL among Chinese, Korean, Thai, and Vietnamese high school seniors.

\section{Methods}

\subsection{Participants}

A total of 1,261 students participated in the survey: 700 male, 543 female, and four unidentified. Fourteen were excluded because of inadequate responses. As shown in Table 2, there were 411 respondents from one school in 
China (44\%), 303 respondents from two schools in Korea (24\%), 295 respondents from one school in Thailand $(19 \%)$, and 295 respondents from one school in Vietnam (24\%).

As shown in Table 5, gender distribution among the participants was 222 male and 189 female Chinese students, 211 male and 92 female Korean students, 97 male and 141 female Thai students, and 170 male and 121 female Vietnamese students. All students were aged 18 or above. Among Chinese students, 20 were 18 years of age $(5 \%), 119$ were 19 years $(29 \%)$, and 272 were 20 years or higher $(66 \%)$. Within Korean students, 234 were 19 years of age $(77 \%)$ and 69 were 20 years or higher $(23 \%)$. Among Thai students, 179 were 18 years of age (75\%), 13 were 19 years $(6 \%)$ and 46 were 20 years or higher $(19 \%)$. All Vietnamese students were 18 years of age.

\subsection{Instruments}

The three components of the questionnaire for adolescents, QOL, ATS, and ADD, were composed and developed from the following research and resources. The questionnaire set consisted of five sections: (1) demographic characteristics (e.g., age and gender); (2) 11 questions regarding QOL from the WHO Quality of Life Assessment instrument (WHOQOL-BREF); (3) 10 questions regarding ATS from a literature review about ethno-cultural aspects of suicide; (4) 11 questions regarding ADD from a validated Multidimensional Orientation Toward Dying-And-Death Inventory; and (5) eight questions regarding suicide ideation; five items from Youth Risk Behavior Survey (YRBS) and three items from the author and associates (CDC, 2009; Erminia and Graham, 2007; Wittkowski, 2001; WHO, 1998).

The five questions from the YRBS regarding suicide ideation were: (1) Did you ever feel so sad or hopeless almost every day for two weeks or more in a row that you stopped doing some usual activities? (2) Did you ever seriously consider attempting suicide? (3) Did you make a plan about how you would attempt suicide? (4) Did you actually attempt suicide that had to be treated by doctors or nurses? (5) How many times did you actually attempt suicide? The authors developed an additional three questions: (6) Did you ever think about committing suicide? (7) Did you ever talk about committing suicide with others? (8) Did you ever threaten to commit suicide? Questions 4 and 5 were used for criterion variables; otherwise, the questions were treated as predictor variables.

The other variables represented in questions in Section 2-QOL, Section 3-ATS, and Section 4-ADD were five-choice Likert scale with the endpoints of Strongly Agree (1) and Strongly Disagree (5). The items with reverse connotation were recoded to Strongly Agree (5) and Strongly Disagree (1) so that all items would align in the same correlated direction. The finalized items with higher scores interpretively indicated increased positive ADD, positive QOL, but negative ATS, i.e., do not favor suicide.

\subsection{Procedures}

The questionnaires were administered in senior high school classes during the summer of 2009. A passive consent letter was attached to the questionnaire to ensure voluntary and anonymous participation. The study protocol was first approved by the University's Institutional Review Board and was submitted to the participating schools for approval. The survey was conducted after approval from all participating sites. The survey administrators informed the students that their participation was voluntary and data would remain confidential and reported without individual identification. Any student was permitted to leave if she or he was not interested in participating in the study; otherwise, the students could complete the questionnaires during the last 25 minutes of class.

\subsection{Statistical Analysis of the Instruments}

SPSS Factor Analysis Procedure was used in order to extract the common predictive factors by eliminating the low contribution of the loading correlation value and the items that were exclusive or least in common (SPSS Inc., 2009). It was used to analyze ADD, QOL, and ATS to determine the coincidence between the data processing factors and the conceptual framework of predesigned factors among the four nations. Exploratory factor analysis was derived from the collective data computation, and then used the formation that fit with the framework's predesigned factors of each of the nations. Calculated values of loading factors signified the quantity of designated common factors. The excluded items that were lower in contributing correlation factors, known as loading factors (Eigenn Value) less than 0.50 , should be eliminated as a criterion variable from the analysis (Tabachnick and Fidell, 2007).

As shown in Table 1, the QOL loading factors coincidentally shared the predictive common profile including the four items that could be characterized in all four nations. It indicated individuals who preferred interacting with friends and family as a dominant social domain called Social Life. This representative factor could be treated as a predictor variable of interpersonal social preference for QOL. From QOL, one outstanding loading factor at 0.747 reflected satisfaction in family life the highest value in Vietnamese participants. The factor analysis 
emphasized that family and friends were considered the preferential components to QOL for adolescents. However, the other aspects in personal leisure, health, body appearance, safety, and spending allowance were shared amongst three nations.

Table 1. Loading Factors on the Quality of Life (QOL) using Factor Analysis among the Chinese, Korean, Thai, and Vietnamese Students

\begin{tabular}{lllll}
\hline Nations & China & Korea & Thailand & Vietnam \\
Quality of Life & QOL & QOL & QOL & QOL \\
\hline I would describe my satisfaction with my overall life & .776 & .644 & .630 & .735 \\
How would you rate your quality of life? & .711 & .700 & .680 & .754 \\
How satisfied are you with personal relationships? & .667 & .733 & .709 & .562 \\
I would describe my satisfaction with my friendships & .641 & .611 & .550 & .534 \\
How often do you have negative feelings, depression? & .581 & & & .500 \\
I would describe my satisfaction with my family life & .556 & & .527 & .747 \\
How satisfied are you with your health? & .549 & .626 & .571 & \\
To what extent is your opportunity for leisure? & .515 & & .468 & .496 \\
Are you able to accept your bodily appearance? & & .489 & .583 & .461 \\
Have you enough money to meet your needs? & & .588 & .484 & .536 \\
How safe do you feel in your daily life? & & .584 & .555 & .465
\end{tabular}

Note. Contributed Loading Factor (Eigenn Value) is between 0 to1.

As illustrated in Table 2, the factor analysis on ADD indicated that the four coincidental common loading factors characterized a profile of accepting death as a natural process with a connotation of uncertain perceptions after death and known as Death with Perception. With some exceptions of high loading factors from Korea and Vietnam, overall the participants held the view that a person needed to be kept alive at all costs. Thai students perceived that the death of a family member would have a deeper impact to their normal life. From the loading factors, Death with Perception for ADD was a candidate for the criterion variable for logistic regression analysis.

Table 2. Loading Factors on the Attitude toward Death-and-Dying (ADD) using Factor Analysis among the Chinese, Korean, Thai and Vietnamese Students

\begin{tabular}{|c|c|c|c|c|}
\hline Nations & China & Korea & Thailand & Vietnam \\
\hline Attitude toward Death-and-Dying & ADD & ADD & ADD & ADD \\
\hline
\end{tabular}

I believe older is last on the list when it comes to receiving medical care.

I am afraid of my dying being prolonged by medical equipment

The idea that my body disappears after my death disturbs me

I am frightened by the idea that all my feelings will stop when I am dead

The thought of the coldness of a corpse terrifies me

$\begin{array}{llll}.690 & .752 & .648 & .736 \\ .665 & .775 & .541 & .707 \\ .595 & .541 & .478 & .689 \\ .576 & .474 & .654 & .561 \\ & & .526 & \end{array}$

I am accepting that even people who are close to me will be dead one day 
Someone who is severely ill could ask the doctor to help them end their life

If I were severely ill with no hope, I would want to be kept alive at all costs

I wish that death-and-dying were more openly discussed in our society.

If I were too ill, the quality of life is more important than how long it lasted.

I believe most people are in pain as death approaches

The coincidental common factor regarding the ATS indicated the four most in common items could be characterized as a profile of an individual's Suicide Rights. The participants perceived that tired of living, financial trouble, incurable illness, and portray of dishonored are components for a solution of Suicide Rights. With the exception of the Korean participants, there were three items that had lower contributions indicating suicide was viewed different from others (Table 3). The coincidental factor can be characterized as a profile of an alternative but undesirable solution to the problem. In addition, Korean and Thai participants perceived that committing suicide is not fair to their relatives.

Table 3. Loading Factors on the Attitude toward Suicide (ATS) Factors using Factor Analysis among the Chinese, Korean, Thai, and Vietnamese Students

\begin{tabular}{lllll}
\hline Nations & China & Korea & Thailand Vietnam \\
\hline Attitude toward Suicide & ATS & ATS & ATS & ATS \\
Someone who is tired of living has the right to kill him/herself & .773 & .815 & .779 & .762 \\
Someone who has gone bankrupt has the right to kill him/herself & .740 & .798 & .753 & .786 \\
Suicide is a possible solution to problems & .647 & & .737 & .717 \\
Someone who is suffering from illness has the right to kill him/herself & .625 & .595 & .692 & .706 \\
A person should never take his/her own life. & .620 & & .655 & .574 \\
Someone who dishonored his/her family has the right to kill him/herself & .607 & .669 & .713 & .704 \\
Suicide can be the only way out of life's problems & .497 & & .752 & .687 \\
People who attempt suicide are mentally ill. & & & & \\
Committing suicide is among the worst things to do to one's relatives. & & .474 & .602 &
\end{tabular}

From the statistical factor analysis and predesigned conceptual framework, three extracted signifying common factors coincided: Social Life, Death with Perception, and Suicide Rights. These three factors were used as the predictors in the logistic regression analysis. The items that contributed to the three criterion groups for all nations were representing variables between ADD, QOL, and ATS presented in Table 4.

Table 4. Three Determinant Domain Factors Conceptually Derived from Internal Consistency With Common Loading Factors on QOL, ATS, and ADD from Each Country

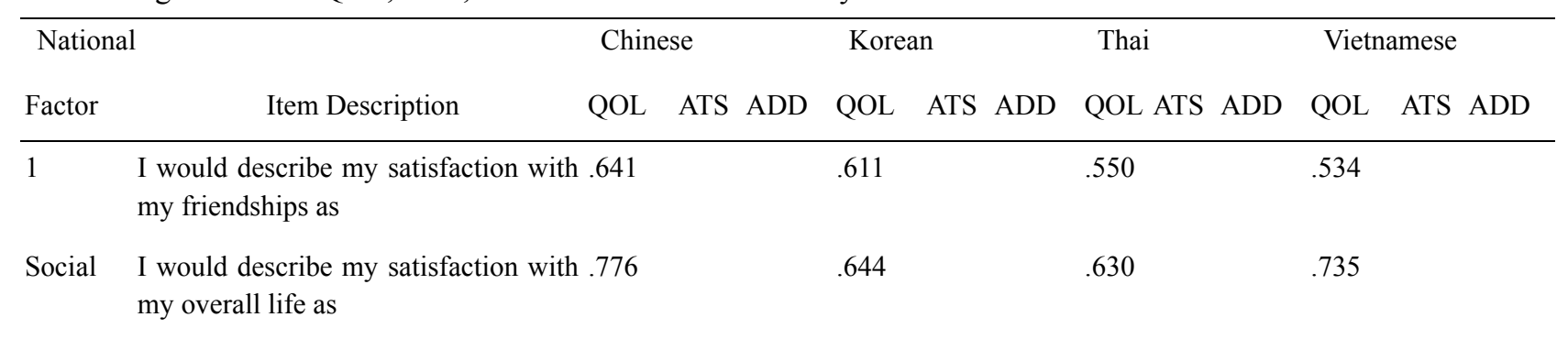




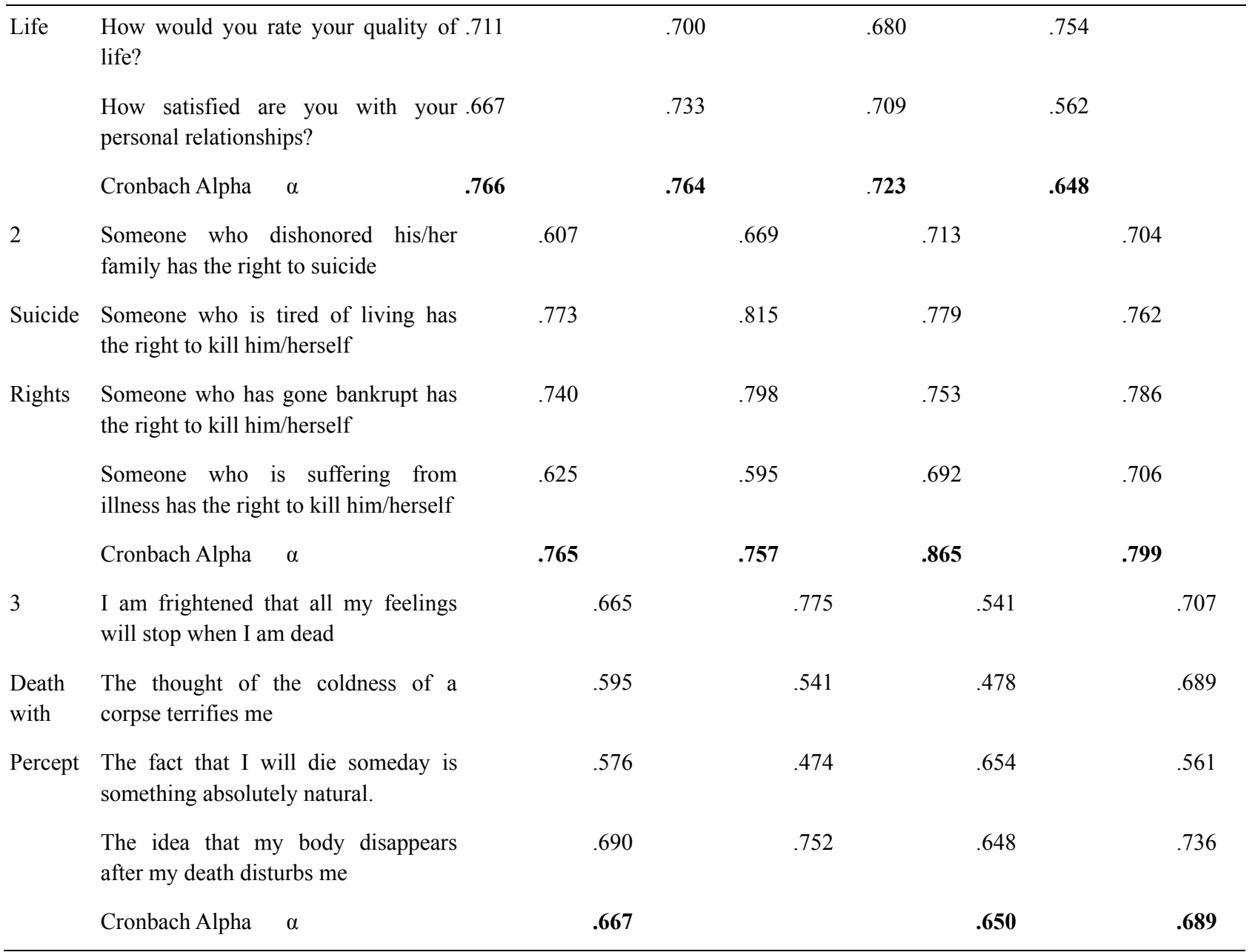

Note. Factor 1 "Social Life" extracted from QOL, Factor 2 "Suicide Rights" extracted from ATS, and Factor 3

"Death with Perception" extracted from ADD

\subsection{Data Analysis}

Statistical analyses were done using the SPSS 17.0 (SPSS Inc., 2009). Chi-square tests of independence were applied to test the relationships between the outcome independent variables (predictors) and the dependent variables (criterion). Pearson 2-tailed correlations analysis was used to determine relationships between outcome variables derived from the factor analysis and the assigned independent variables designated significance at 0.01 levels.

Among the four nations, the differences between the ADD, QOL, and ATS were examined a high order of interaction using 4-way ANOVA. Post hoc multiple comparison tests based on Tukey's Honestly Significant Difference were used to make all pairwise comparisons between nations. The harmonic mean of the group sizes was used due to unequal sample sizes. The level of significance was also assigned at $p=.01$.The variables with bivariate of probability $p$-value $\leq .01$ in chi-square tests were entered into the logistic regression models. Adjusted odds ratios (AOR) of each single predictor were reported with a $99 \%$ confidence of interval (CI) after adjusting for gender, age groups, and class standings.

\section{Results}

\subsection{The Demographic Descriptive Characteristic}

Overall, the four countries demonstrated during the past 12 months, $20.4 \%$ of the respondents expressed some level of depression prolonging sadness or hopelessness; and 3\% admitted to attempting suicide at least once and, in some cases, 8 to 15 times (See Table 5). The demographic descriptive statistics of the Chinese, Korean, Thai, and Vietnamese students illustrated that gender and age group, sadness, suicidal thoughts, suicidal behavior, and attempted suicide was initiated at some point in the past 12 months. 
This initial stage of suicide thought references sustained sadness, hopelessness, or feeling of depression in the past 12 months. Vietnamese students responded with a very high percentage of $37.2 \%$, Korean at $22.2 \%$, Thai at $16 \%$, and Chinese the lowest at $9.4 \%$. On the second phase, suicide planning, Vietnamese students were highest at $26.8 \%$, Chinese second at $21.7 \%$, Koreans third at $20.9 \%$, and lastly Thai at $16.8 \%$. It was indicated that Chinese students had a tendency to produce immediate thoughts of suicide in a shorter period of time than 12 months. The last phase, suicide attempt, Vietnamese students had the highest rate at $5.2 \%$, Chinese at $2.7 \%$, Korean at $2.6 \%$, and Thai students were the lowest at $1.7 \%$. In the correlation analysis, the findings showed a significant association between those who attempted suicide and those with suicide ideation (See Table 5).

Table 5. Descriptive characteristics of Chinese, Korean, Thai, and Vietnamese Students

\begin{tabular}{lllllllllll}
\hline & & \multicolumn{3}{c}{ China } & \multicolumn{3}{c}{ Korea } & \multicolumn{2}{c}{ Thailand } & \multicolumn{2}{c}{ Vietnam } \\
& & $\mathrm{n}$ & $\%$ & $\mathrm{~N}$ & $\%$ & $\mathrm{n}$ & $\%$ & $\mathrm{~N}$ & $\%$ \\
\hline Gender & Male & 222 & 54.0 & 211 & 69.6 & 97 & 40.8 & 170 & 57.6 \\
& Female & 189 & 46.0 & 92 & 30.4 & 141 & 59.2 & 121 & 41.0 \\
Age in years & 18 & 20 & 4.9 & - & - & 179 & 75.2 & 295 & 100.0 \\
& 19 & 119 & 29.0 & 234 & 77.2 & 13 & 5.5 & - & - \\
& $20+$ & 272 & 66.2 & 69 & 22.8 & 46 & 19.3 & - & - \\
Sustained Sadness & Yes & 38 & 9.4 & 67 & 22.2 & 38 & 16.0 & 109 & 37.2 \\
& No & 367 & 90.6 & 235 & 77.8 & 200 & 84.0 & 184 & 62.8 \\
Suicidal Behavior & Yes & 88 & 21.7 & 63 & 20.9 & 40 & 16.8 & 77 & 26.3 \\
& No & 318 & 78.3 & 239 & 79.1 & 198 & 83.2 & 216 & 73.7 \\
Suicide Attempted & Yes & 11 & 2.7 & 8 & 2.6 & 4 & 1.7 & 15 & 5.2 \\
& No & 394 & 97.3 & 295 & 97.4 & 234 & 98.3 & 276 & 94.8 \\
\hline
\end{tabular}

\subsection{Comparing among the Four Countries}

The first goal of analysis was to compare suicide thought, ATS, ADD, and QOL associations to suicide ideation among the nations, age groups, and genders. As illustrated in Tables 6 and 7, the sustained sadness or hopeless feelings within the past 12 months were significantly associated with the four countries, with the lowest rate $9.4 \%$ in China and the highest rate $37.2 \%$ in Vietnam. The results of the chi-square test determined the $\chi^{2}$ value of 84.82 and yielded a significance level less than 0.001 . Yet, reports of suicide ideation ranged from $16.8 \%$ to $26.3 \%$ and among the nations where chi-square value yielded at 7.11 , it did not show a significant association at 0.01 levels (See Table 6).

Table 6. Sustained sadness or hopeless feelings and suicide ideation

\begin{tabular}{|c|c|c|c|c|c|c|c|}
\hline \multirow[t]{2}{*}{ Country } & \multirow{2}{*}{$\begin{array}{l}\begin{array}{l}\text { China } \\
(\%)\end{array} \\
N=411\end{array}$} & \multirow{2}{*}{$\begin{array}{l}\begin{array}{l}\text { Korea } \\
(\%)\end{array} \\
\mathrm{N}=303\end{array}$} & \multirow{2}{*}{$\begin{array}{l}\text { Thailand } \\
(\%) \\
\mathrm{N}=238\end{array}$} & \multirow{2}{*}{$\begin{array}{l}\text { Vietnam } \\
(\%) \\
\mathrm{N}=295\end{array}$} & \multirow[t]{2}{*}{$\chi^{2}$} & \multirow[t]{2}{*}{$d f$} & \multirow[t]{2}{*}{$p$} \\
\hline & & & & & & & \\
\hline \multicolumn{8}{|l|}{ Sadness } \\
\hline Yes & 9.4 & 22.2 & 16.0 & 37.2 & 84.82 & 3 & $*<.001$ \\
\hline No & 90.6 & 77.8 & 84.0 & 62.8 & & & \\
\hline \multicolumn{8}{|c|}{ Suicide Ideation } \\
\hline Yes & 21.7 & 20.9 & 16.8 & 26.3 & 7.11 & 3 & .068 \\
\hline No & 78.3 & 79.1 & 83.2 & 73.7 & & & \\
\hline
\end{tabular}

Note. Sadness $=$ sustained sadness or hopeless feelings 
From students who reported having suicide ideation in each individual country, suicide ideation was associated with gender, age, and sustained sadness or hopeless feelings. Statistically suicide ideation was not significantly associated among the four countries in gender and age group. Suicide ideation was only slightly significantly associated with gender in Korean high school students at 0.05 levels $(p=0.04$; See Table 7). High school students who reported suicide ideation included elements of seriously considering attempting suicide, a plan made about how to attempt suicide, and threatening attempted suicide by showing suicidal behaviors were lowest in Thailand at $16.8 \%$ and the highest in Vietnam at $26.3 \%$. In bivariate analysis, there were significant associations of suicide ideation to the sadness feelings across the nations at 0.01 levels.

Table 7. Bivariate associations of suicide ideation to gender, age, and sustained sadness feelings

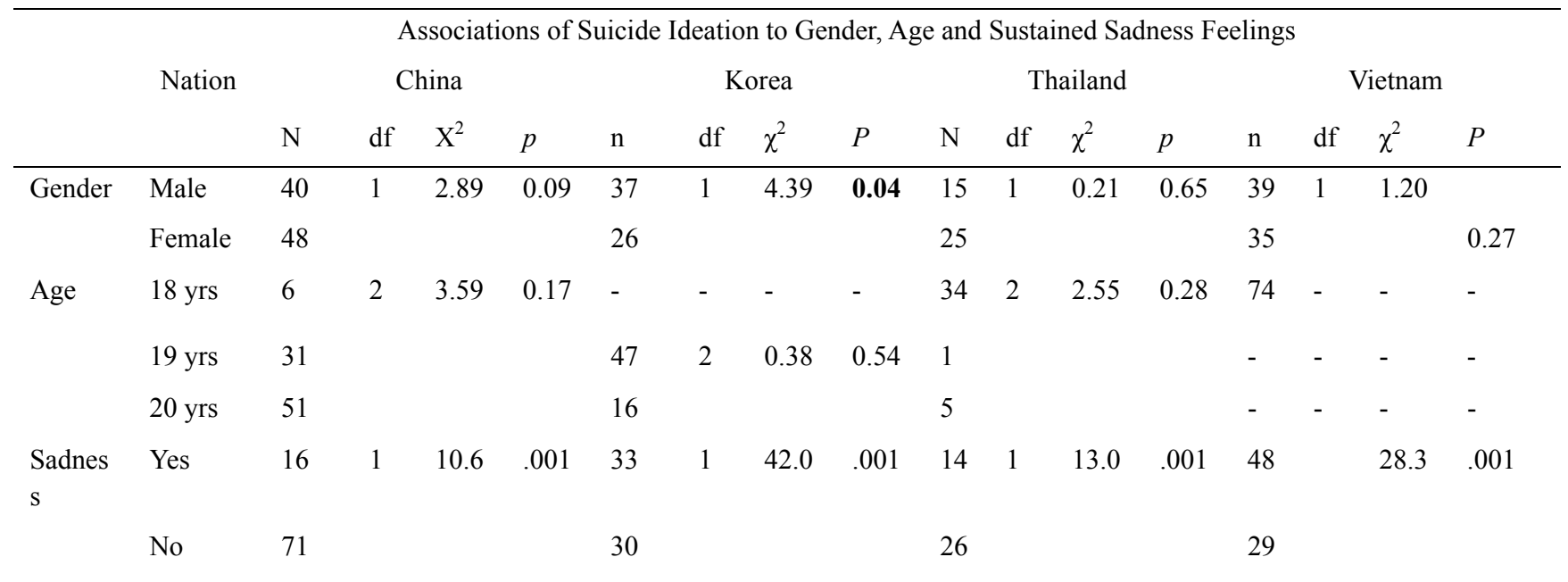

Note. For gender: $\mathrm{n}=88$ in China, $\mathrm{n}=63$ in Korea, $\mathrm{n}=40$ in Thailand, and $\mathrm{n}=74$ in Vietnam.

For age group: $\mathrm{n}=88$ in China, $\mathrm{n}=63$ in Korea, $\mathrm{n}=40$ in Thailand, and $\mathrm{n}=77$ in Vietnam.

For sadness: $n=87$ in China, $n=63$ in Korea, $n=40$ in Thailand, and $n=77$ in Vietnam.

\subsection{Correlations among ATS, $A D D$, and $Q O L$ with Suicidal Component}

The second task of analysis was to determine the correlations between each phase of suicidal thoughts, suicidal behaviors, and suicide attempts and how they related to ATS, ADD, and QOL factors among the participants. The results showed that only ADD stood independently and did not show a significant correlation to the other variables. The suicidal thought element of sadness was significantly correlated to actual suicide attempted at 0.01 levels (See Table 8). Among ADD, QOL, and ATS, only ATS was significantly correlated to actual suicide attempted, suggesting that ADD or QOL alone was not a primary predictor for suicide ideation.

Table 8. Pearson correlation among countries in each phase of suicide thought, suicide behavior, and suicide attempt

\section{Pearson Correlations 2-tailed}

\begin{tabular}{llllllll}
$\mathrm{N}=1238$ & & Sadness & $\begin{array}{l}\text { Attempted } \\
\text { Suicide }\end{array}$ & & $\begin{array}{l}\text { QOL } \\
\text { Suicidal } \\
\text { Behavio }\end{array}$ & ATS & ADD \\
\hline Sadness & Pearson Correlation & 1 & $-.116^{* *}$ & $.146^{* *}$ & $-.276^{* *}$ & $.089^{* *}$ & .010 \\
& Sig. (2-tailed) & & .000 & .000 & .000 & .002 & .729 \\
\multirow{4}{*}{ Attempt suicide } & Pearson Correlation & $-.116^{* *}$ & 1 & -.040 & $.184^{* *}$ & $-.212^{* *}$ & -.010 \\
& Sig. (2-tailed) & .000 & & .157 & .000 & .000 & .726 \\
QOL & Pearson Correlation & $.146^{* *}$ & -.040 & 1 & $-.108^{* *}$ & $.210^{* *}$ & $.071^{*}$ \\
& Sig. (2-tailed) & .000 & .157 & & .000 & .000 & .012 \\
\hline
\end{tabular}




\begin{tabular}{llllllll}
\hline Suicidal Behavior & Pearson Correlation & $-.276^{* *}$ & $.184^{* *}$ & $-.108^{* *}$ & 1 & $-.210^{* *}$ & .050 \\
& Sig. (2-tailed) & .000 & .000 & .000 & & .000 & .079 \\
ATS & Pearson Correlation & $.089^{* *}$ & $-.212^{* *}$ & $.210^{* *}$ & $-.210^{* *}$ & 1 & -.016 \\
& Sig. (2-tailed) & .002 & .000 & .000 & .000 & & .562 \\
ADD & Pearson Correlation & .010 & -.010 & $.071^{*}$ & .050 & -.016 & 1 \\
& Sig. (2-tailed) & .729 & .726 & .012 & .079 & .562 & \\
\hline
\end{tabular}

**. Correlation is significant at the 0.01 level (2-tailed).

*. Correlation is significant at the 0.05 level (2-tailed).

\subsection{Predictive Factors of Suicide Ideation Relating to $A T S, A D D$, and $Q O L$}

The third objective of the analysis was to examine associative predictive factors of suicide ideation relating to ATS, ADD, and QOL perceptions with the element of sustained sadness feelings among the participants. Logistic regression was used to confirm the predictable factors association between suicide ideation with the element of sustained sadness feelings at the significance level 0.01 across all four countries with and without controlling for gender as shown in Table 9. Those who had reported sustained sadness feelings in the last 12 months seemed to suggest that they had a sense of no alternative and focused on suicide ideation.

Table 9. Logistic regression of suicide ideation among the Chinese, Korean, Thai, and Vietnamese students

\begin{tabular}{|c|c|c|c|c|c|c|c|c|c|c|c|c|}
\hline \multirow[b]{2}{*}{ Sadness } & \multicolumn{3}{|c|}{$\begin{array}{l}\text { China } \\
(\mathrm{n}=411), \mathrm{R}^{2}=0.04\end{array}$} & \multicolumn{3}{|c|}{$\begin{array}{l}\text { Korea } \\
(\mathrm{n}=303), \mathrm{R}^{2}=0.18\end{array}$} & \multicolumn{3}{|c|}{$\begin{array}{l}\text { Thailand } \\
(\mathrm{n}=238), \mathrm{R}^{2}=0.08\end{array}$} & \multicolumn{3}{|c|}{$\begin{array}{l}\text { Vietnam } \\
(\mathrm{n}=295), \mathrm{R}^{2}=0.13\end{array}$} \\
\hline & AOR & $99 \% \mathrm{CI}$ & $P$ & AOR & $99 \% \mathrm{CI}$ & $p$ & AOR & $99 \% \mathrm{CI}$ & $p$ & AOR & $99 \% \mathrm{CI}$ & $p$ \\
\hline No & 1.00 & Range & .002 & 1.00 & Range & $<.001$ & 1.00 & Range & .001 & 1.00 & Range & $<.001$ \\
\hline Yes & 3.03 & $1.52-6.07$ & & 6.63 & $3.59-12.25$ & & 3.90 & $1.79-8.49$ & & 4.21 & $2.43-7.28$ & \\
\hline
\end{tabular}

When compared to a logistic regression analysis that controlled for gender, suicide ideation was significantly associated and predictive across all four nations to sustained sadness feelings at the significance level 0.01 . However, the interval range of acceptance was varied (Table 10).

Table 10. Logistic regression of suicide ideation among the Chinese, Korean, Thai, and Vietnamese students with controlling for gender

\begin{tabular}{|c|c|c|c|c|c|c|c|c|c|c|c|c|}
\hline \multirow[b]{2}{*}{ Sadness } & \multicolumn{3}{|c|}{$\begin{array}{l}\text { China } \\
(\mathrm{n}=411), \mathrm{R}^{2}=0.05\end{array}$} & \multicolumn{3}{|c|}{$\begin{array}{l}\text { Korea } \\
(\mathrm{n}=303), \mathrm{R}^{2}=0.20\end{array}$} & \multicolumn{3}{|c|}{$\begin{array}{l}\text { Thailand } \\
(\mathrm{n}=238), \mathrm{R}^{2}=0.08\end{array}$} & \multicolumn{3}{|c|}{$\begin{array}{l}\text { Vietnam } \\
(\mathrm{n}=295), \mathrm{R}^{2}=0.13\end{array}$} \\
\hline & $\mathrm{OR}^{\dagger}$ & $99 \% \mathrm{CI}$ & $P$ & $\mathrm{OR}^{\dagger}$ & $99 \% \mathrm{CI}$ & $P$ & $\mathrm{OR}^{\dagger}$ & $99 \% \mathrm{CI}$ & $P$ & $\mathrm{OR}^{\dagger}$ & $99 \% \mathrm{CI}$ & $P$ \\
\hline No & 1.00 & Range & .001 & 1.00 & Range & .001 & 1.00 & Range & .001 & 1.00 & Range & $<.001$ \\
\hline Yes & 3.22 & $1.60-6.50$ & & 6.85 & $3.67-12.78$ & & 3.90 & $1.79-8.49$ & & 4.10 & $2.35-7.16$ & \\
\hline
\end{tabular}

${ }^{\dagger}$ Controlling for gender

Table 11 shows a logistic regression of suicide ideation among the Chinese, Korean, Thai, and Vietnamese students in terms of QOL, ADD, and ATS. Suicide ideation was associated with a negative attitude toward suicide in all four countries with and without controlling for gender, indicating that those who were not favorable toward suicide were less likely to have suicide ideation. 
Table 11. Logistic regression of suicide ideation among the Chinese, Korean, Thai, and Vietnamese high school students in terms of QOL, ADD, and ATS without controlling for gender

\begin{tabular}{|c|c|c|c|c|c|c|c|c|c|c|c|c|}
\hline & \multicolumn{2}{|c|}{$\begin{array}{l}\text { China } \\
(\mathrm{n}=411), \mathrm{R}^{2}=0.07\end{array}$} & \multirow[b]{2}{*}{$p$} & \multicolumn{3}{|c|}{$\begin{array}{l}\text { Korea } \\
(n=303), R^{2}=0.13\end{array}$} & \multicolumn{3}{|c|}{$\begin{array}{l}\text { Thailand } \\
(\mathrm{n}=238), \mathrm{R}^{2}=0.06\end{array}$} & \multicolumn{3}{|c|}{$\begin{array}{l}\text { Vietnam } \\
(\mathrm{n}=295), \mathrm{R}^{2}=0.16\end{array}$} \\
\hline & OR & $99 \% \mathrm{CI}$ & & OR & $99 \%$ CI & $p$ & OR & $99 \%$ CI & $p$ & OR & $99 \% \mathrm{CI}$ & $p$ \\
\hline \multirow[t]{3}{*}{ QOL } & 0.47 & $0.33-0.67$ & .001 & 3.66 & $2.16-6.20$ & .001 & 0.44 & $0.25-0.78$ & .01 & 0.27 & $0.17-0.44$ & .001 \\
\hline & \multicolumn{2}{|c|}{$\begin{array}{l}\text { China } \\
(\mathrm{n}=411), \mathrm{R}^{2}=0.10\end{array}$} & & \multicolumn{3}{|c|}{$\begin{array}{l}\text { Korea } \\
(\mathrm{n}=303), \mathrm{R}^{2}=0.02\end{array}$} & \multicolumn{2}{|c|}{$\begin{array}{l}\text { Thailand } \\
(\mathrm{n}=238), \mathrm{R}^{2}=0.03\end{array}$} & & \multicolumn{2}{|c|}{$\begin{array}{l}\text { Vietnam } \\
(\mathrm{n}=295), \mathrm{R}^{2}=0.11\end{array}$} & \\
\hline & OR & $99 \% \mathrm{CI}$ & $p$ & OR & $99 \% \mathrm{CI}$ & $p$ & OR & $99 \% \mathrm{CI}$ & $p$ & OR & $99 \% \mathrm{CI}$ & $p$ \\
\hline \multirow[t]{3}{*}{ ATS } & 0.42 & $0.30-0.60$ & .001 & 0.66 & $0.45-0.96$ & .05 & 0.69 & $0.48-0.99$ & .05 & 0.45 & $0.32-0.63$ & .001 \\
\hline & \multicolumn{3}{|c|}{$(\mathrm{n}=411), \mathrm{R}^{2}=0.03$} & \multicolumn{3}{|c|}{$(\mathrm{n}=303), \mathrm{R}^{2}=0.002$} & \multicolumn{2}{|c|}{$(\mathrm{n}=238), \mathrm{R}^{2}=0.001$} & & \multicolumn{2}{|c|}{$(\mathrm{n}=295), \mathrm{R}^{2}<.001$} & \\
\hline & OR & $99 \% \mathrm{CI}$ & $p$ & OR & $99 \% \mathrm{CI}$ & $p$ & OR & $99 \% \mathrm{CI}$ & $p$ & OR & $99 \% \mathrm{CI}$ & $p$ \\
\hline ADD & 1.66 & $1.16-2.38$ & .01 & 1.12 & $0.69-1.80$ & .05 & 1.13 & $0.79-1.63$ & .05 & 0.99 & $0.71-1.38$ & $>.05$ \\
\hline
\end{tabular}

Note. $\mathrm{QOL}=$ quality of life; ATS $=$ attitude toward suicide; ADD $=$ attitude toward death and dying.

Adjusted odds ratios (AOR) with a $99 \%$ confidence of interval (CI) after adjusting for gender, age groups, and class standings at level of significance $\mathrm{p}=.01$.

The results for controlling for gender were similar except the confidence intervals were slightly different (See Table 12). Suicide ideation was significantly associated with optimistic QOL in all four countries with and without controlling for gender. It is reflecting different values that students in China, Thailand, and Vietnam who perceived a positive QOL were less likely to have suicide ideation (odd ratios $<1.0$ ), whereas in Korean students, those who had positive QOL were illustrated more likely (odd ratios $>1.0$ ) to have suicide ideation. In contrast, suicide ideation was significantly associated with the optimistic ADD only in Chinese students with and without controlling for gender. It was indicating that those who were positive about death-and-dying were more likely to have suicide ideation. However, the association between suicide ideation and ADD did not yield a significant level in Korean, Thai, and Vietnamese students.

Table 12. Logistic regression of suicide ideation among the Chinese, Korean, Thai, and Vietnamese high school students with controlling for gender

\begin{tabular}{|c|c|c|c|c|c|c|c|c|c|c|c|c|}
\hline & \multicolumn{2}{|c|}{$\begin{array}{l}\text { China } \\
(\mathrm{n}=411), \mathrm{R}^{2}=0.09\end{array}$} & \multirow[b]{2}{*}{$p$} & \multicolumn{2}{|c|}{$\begin{array}{l}\text { Korea } \\
(\mathrm{n}=303), \mathrm{R}^{2}=0.17\end{array}$} & \multirow[b]{2}{*}{$p$} & \multicolumn{2}{|c|}{$\begin{array}{l}\text { Thailand } \\
(\mathrm{n}=238), \mathrm{R}^{2}=0.07\end{array}$} & \multirow[b]{2}{*}{$p$} & \multicolumn{2}{|c|}{$\begin{array}{l}\text { Vietnam } \\
(\mathrm{n}=295), \mathrm{R}^{2}=0.15\end{array}$} & \multirow[b]{2}{*}{$p$} \\
\hline & AOR & $99 \% \mathrm{CI}$ & & AOR & $99 \% \mathrm{CI}$ & & AOR & $99 \%$ CI & & AOR & $99 \% \mathrm{CI}$ & \\
\hline \multirow[t]{3}{*}{ QOL } & 0.45 & $0.31-0.64$ & .001 & 4.06 & $2.37-6.95$ & .001 & 0.41 & $0.23-0.74$ & .003 & 0.28 & $0.17-0.46$ & .001 \\
\hline & \multicolumn{2}{|c|}{$\begin{array}{l}\text { China } \\
(\mathrm{n}=411), \mathrm{R}^{2}=0.12\end{array}$} & & \multicolumn{2}{|c|}{$\begin{array}{l}\text { Korea } \\
(\mathrm{n}=303), \mathrm{R}^{2}=0.04\end{array}$} & & \multicolumn{2}{|c|}{$\begin{array}{l}\text { Thailand } \\
(\mathrm{n}=238), \mathrm{R}^{2}=0.05\end{array}$} & & \multicolumn{2}{|c|}{$\begin{array}{l}\text { Vietnam } \\
(\mathrm{n}=295), \mathrm{R}^{2}=0.12\end{array}$} & \\
\hline & AOR & $99 \% \mathrm{CI}$ & $p$ & AOR & $99 \%$ CI & $p$ & AOR & $99 \%$ CI & $p$ & AOR & $99 \%$ CI & $p$ \\
\hline \multirow[t]{3}{*}{ ATS } & 0.39 & $0.27-0.56$ & .001 & 0.65 & $0.45-0.94$ & .02 & 0.64 & $0.43-0.94$ & $<.02$ & 0.44 & $0.31-0.63$ & .001 \\
\hline & \multicolumn{2}{|c|}{$\begin{array}{l}\text { China } \\
(\mathrm{n}=411), \mathrm{R}^{2}=0.05\end{array}$} & & \multicolumn{2}{|c|}{$\begin{array}{l}\text { Korea } \\
(\mathrm{n}=303), \mathrm{R}^{2}=0.003\end{array}$} & & \multicolumn{2}{|c|}{$\begin{array}{l}\text { Thailand } \\
(\mathrm{n}=238), \mathrm{R}^{2}=0.003\end{array}$} & & \multicolumn{2}{|c|}{$\begin{array}{l}\text { Vietnam } \\
(\mathrm{n}=295), \mathrm{R}^{2}=.006\end{array}$} & \\
\hline & AOR & $99 \%$ CI & $p$ & AOR & $99 \% \mathrm{CI}$ & $p$ & AOR & $99 \%$ CI & $p$ & AOR & $99 \% \mathrm{CI}$ & $P$ \\
\hline $\mathrm{ADD}$ & 1.78 & $1.22-2.59$ & .003 & 1.17 & $0.81-1.68$ & $>.05$ & 1.13 & $0.70-1.83$ & $>.05$ & 0.99 & $0.70-1.40$ & $>.05$ \\
\hline
\end{tabular}

Using mean comparisons, there were significant differences among the Chinese, Korean, Thai, and Vietnamese students in QOL, ATS, and ADD based on the results of ANOVA. Post hoc tests show that Thai students had the 
highest scores for all three factors: QOL, ATS, and ADD (See Table 13). Specifically, Thai students had a significantly higher mean score $(\mathrm{M}=3.85, \mathrm{SD}=0.61)$ for $\mathrm{QOL}$ than Chinese $(\mathrm{M}=3.57, \mathrm{SD}=0.67)$, Korean $(\mathrm{M}=$ 2.62, $\mathrm{SD}=0.61)$, and Vietnamese students $(\mathrm{M}=3.46, \mathrm{SD}=0.63)$. Also, Thai students had a significantly higher mean score $(\mathrm{M}=4.25, \mathrm{SD}=0.82)$ for negative ATS than the Chinese $(\mathrm{M}=3.72, \mathrm{SD}=0.73)$, Korean $(\mathrm{M}=3.71$, $\mathrm{SD}=0.78)$, and Vietnamese $(\mathrm{M}=3.86, \mathrm{SD}=0.82)$. In addition, Thai students had significantly higher mean scores $(\mathrm{M}=3.53, \mathrm{SD}=0.72)$ for negative $\mathrm{ADD}$ than Chinese $(\mathrm{M}=3.29, \mathrm{SD}=0.68)$, Korean $(\mathrm{M}=3.26, \mathrm{SD}=0.76)$, and Vietnamese students $(\mathrm{M}=3.34, \mathrm{SD}=0.78)$. However, the Chinese $(\mathrm{M}=3.57, \mathrm{SD}=0.67)$ and Vietnamese $(\mathrm{M}=$ $3.46, \mathrm{SD}=0.63)$ students had higher scores for $\mathrm{QOL}$ than Korean students $(\mathrm{M}=2.62, \mathrm{SD}=0.61$; See Table 13$)$.

Table 13. Mean differences in QOL, ATS, and ADD between the Chinese, Korean, Thai, and Vietnamese students

\begin{tabular}{lllllllllllll}
\hline & China & \multicolumn{4}{c}{ Korea } & \multicolumn{4}{c}{ Thailand } & \multicolumn{3}{c}{ Vietnam } \\
& $\mathrm{N}$ & Mean & SD & $\mathrm{N}$ & Mean & SD & N & Mean & SD & N & Mean & SD \\
\hline QOL & 409 & 3.57 & 0.67 & 303 & 2.62 & 0.61 & 238 & 3.85 & 0.61 & 295 & 3.46 & 0.63 \\
ATS & 405 & 3.72 & 0.73 & 302 & 3.71 & 0.78 & 238 & 4.25 & 0.82 & 291 & 3.86 & 0.82 \\
ADD & 411 & 3.29 & 0.68 & 303 & 3.26 & 0.76 & 238 & 3.53 & 0.72 & 295 & 3.34 & 0.78 \\
\hline
\end{tabular}

Note. Leven's test for QOL, ATS, and ADD were not significant.

The harmonic mean of the group sizes was used due to unequal sample sizes.

\section{Discussion}

The findings of this study indicated that $21.7 \%$ of Chinese, $20.9 \%$ of Korean, $16.8 \%$ of Thai, and $26.3 \%$ of Vietnamese students exhibited suicidal behavior in the past 12 months. Suicidal behavior was significantly associated with sustained sadness feelings, ATS, and optimistic QOL in all four countries. Suicidal behavior was significantly associated with optimistic ADD only in Chinese students. Also, there were significant differences among Chinese, Korean, Thai, and Vietnamese students in QOL, ATS, and ADD.

There are several implications from the findings of this study. First, although the findings were based on a self-reported survey that had some degree of deviations among countries, it revealed some existing patterns of suicide prevalence among high school students in Asian countries. More exploratory research is needed in the future. Second, this preliminary study revealed that the accumulation of daily unresolved dissatisfaction may lead to a continuum of serious negative life events that may further lead to suicide ideation prevalence. The comprehensive definition of suicide ideation could help in developing an instrument that could be used to monitor and identify sustained sadness in school age adolescents. In these Asian countries, the identified status in physical health, social relationships, psychological health, and environmental health in the adolescents could help prevent serious life tragedies using the study predictors placed in an intervention program. Third, from these findings, a school health counseling program would be beneficial to identify students who need help finding alternative solutions to suicide ideation. However, counseling roles are often integrated with the role of the homeroom teacher in Asian schools rather than having a designated program as in Western schools.

Unlike the college students as earlier mentioned or in the Western school system, high school seniors of these countries had to compete in at least two major conditions of expectation in academic life, the graduation and the university entrance examination. Many students were convinced or pressured for academic preparation since grade school with additional personal tutoring sessions, private or commercial, during odd hours and on weekends. These stressors were national assets that related to the educational system and social value for educational achievement. There was an indicator that showed students who did not accumulate depression in the past 12 months but had an immediate emerging suicidal thought. This educational system stressor alone needs to be carefully studied. By word of mouth, many people have heard stories of suicide being caused by students' academic failure. The practice was a concern and an issue from the beginning but the Eastern culture's policy making was so dominate and not give enough attention to the problem. Certainly, it is a problem that needs to be recognized and it needs to be evidently verified.

Furthermore, Asian high school students are not encouraged to seek professional counseling services regardless of their obvious needs for those services (Chang, 2008). Often, the counseling office is considered a function of disciplining troubled students instead of providing comfort solutions. Therefore, it is recommended that a 
school-health counseling program must be established and designated to provide the necessary services relevant to managing mental and psychological problems in Asian high school students. Secondly, adequate education, outreach, and media campaigns should be conducted to inform students relating to the mental health issues. Thirdly, schools need to establish a strategy to encourage students to seek professional help before suicide ideation further develops. Fourthly, more fragmentation differences in culture and religion related factors should be included to be further examined as predictors associated with suicide ideation. Lastly, the education system policy, from grade school through college, for tracking high school students for future careers and opportunities needs to be evaluated and should include alternative choices away from the conventional practice.

\subsection{Limitations}

The findings of this study must be considered in light of its limitations. First, the larger sample size in this study could yield higher power to the generalization of the population. Second, some factors related to suicide among high school students were not included in the study, such as a wider range of age groups and geographical types of school settings. In addition, religious beliefs could come into play in part of ATS. The study showed that the younger age students held a higher degree of emotional decision. A future study should include students from $9^{\text {th }}$ through $12^{\text {th }}$ grade. Third, the extracting common factor method used in this study could leave out some interactions or other details to examine wider dimensions of predictor elements of suicide prevalence among high school students. For example, the standard hopelessness scales, such as the Beck HopelessnessScale43, may be incorporated with the WHOQOL-BREF. In the future, this may be considered to open the exploration of effects of depression factors leading to suicide ideation among Asian high school students.

\subsection{Conclusions}

From the results of this study, findings may contribute knowledge and some degree of understanding of suicidal perceptions and behaviors among high school students in Asian countries. Findings of this preliminary study may help provide a fundamental acknowledgement to high school administrators and health educators in the Asian countries to be aware of factors that affect quality of life relating to the continuum stages of suicide commitment.

\section{References}

Andress, V. (1996). The crisis of suicide. Ministry Magazine International Journal for Pastors. Retrieved from http://www.ministrymagazine.org/archive/1996/July/the-crisis-of-suicide (June, 15, 2011)

Ben Park, B. C., \& Lester, D. (2006). Social integration and suicide in South Korea. Crisis, 27, 48-50. http://dx.doi.org/10.1027/0227-5910.27.1.48

Bertolote, J. M., \& Fleischmann, A. (2002). Suicide and psychiatric diagnosis: A worldwide perspective. World Psychiatry, 1, 181-185.

Centers for Disease Control and Prevention. (2009). 2009 State and Local Youth Risk Behavior Survey. Retrieved from http://www.cdc.gov/HealthyYouth/yrbs/pdf/questionnaire/2009HighSchool.pdf (January 12, 2011)

Centers for Disease Control and Prevention. (2010). Injury Prevention and Control: Violence Prevention. Retrieved from http://www.cdc.gov/ViolencePrevention/suicide/definitions.html (June 9, 2012)

Chang, H. (2008). Help-seeking for stressful events among Chinese college students in Taiwan: Roles of gender, prior history of counseling, and help seeking attitudes. Journal of College Student Development, 49, 41-51. http://dx.doi.org/10.1353/csd.2008.0003

Erminia, C., \& Graham, M. (2007). Ethnocultural aspects of suicide in young people: A systematic literature review part 2: Risk factors, precipitating agents, and attitudes toward suicide. Suicide \& Life-ThreateningBehavior, 37, 222-237. http://dx.doi.org/10.1521/suli.2007.37.2.222

Hawton, K., \& van Heeringen, K. (2009). Suicide. Lancet, 373, 1372-1381. http://dx.doi.org/10.1016/S0140-6736(09)60372-X

Kay, N., Li K., Xiao X., Nokkaew, N., \& Park, B. (2009). Hopelessness and suicidal behavior among Chinese, Thai and Korean college students and predictive effects of the World Health Organization's WHOQOL-BREF. International Electronic Journal of Health Education, 12, 16-32.

O'Connor, R., \& Sheehy, N. (2000). Understanding suicidal behavior (pp. 33-37). Leicester, UK: BPS Books. 
Page, R. M., Yanagishita, J., Suwanteerangkul, J., Zarco, E. P., Lee, C. M., \& Miao, N, F. (2006). Hopelessness and loneliness among suicide attempters in school-based samples of Taiwanese, Philippine and Thai Adolescents. School Psychology International, 27, 583-598. http://dx.doi.org/10.1177/0143034306073415

Pirruccello, L. M. (2010). Preventing adolescent suicide: A community takes action. Journal of Psychosocial Nursing \& Mental Health Services, 48, 34-41. http://dx.doi.org/10.3928/02793695-20100303-01

Ruangkanchanasetr, S., Plitponkarnpim, A., Hetrakul, P., \& Kongsakon, R. (2005). Youth risk behavior survey: Bangkok, Thailand. Journal of Adolescent Health, 36, 227-235. http://dx.doi.org/10.1016/j.jadohealth.2004.01.013

Safsten, B. J. (2004). The suicide crisis. Catholic Medical Quarterly. Retrieved from http://www.catholicdoctors.org.uk/CMQ/CMQ_full_frame.htm (June 15, 2011)

SPSS Inc. (2009). SPSS statistics base 17.0 user's guide. Retrieved from http://www.hks.harvard.edu/fs/pnorris/Classes/A\%20SPSS\%20Manuals/SPSS\%20Statistcs\%20Base\%20Us er's\%20Guide\%2017.0.pdf (January 12, 2011)

Tabachnick, B. G., \& Fidell, L. S. (2007). Using multivariate statistics (5th ed.). Needham Heights, MA: Allyn $\&$ Bacon.

Wei, K. C., \& Chua, H. C. (2008). Suicide in Asia. International Review of Psychiatry, 20, 434-440. http://dx.doi.org/10.1080/09540260802397446

Wittkowski, J. (2001). The construction of the multidimensional orientation toward dying and death inventory (Moddi-F). Death Studies, 25, 479-495. http://dx.doi.org/10.1080/07481180126858

World Health Organization. (1998). WHOQOL user manual. Retrieved from http://www.who.int/mental_health/evidence/who_qol_user_manual_98.pdf(December 9, 2010)

World Health Organization. (2006). World mental health day: Building awareness - reducing risks: Suicide and mental illness. Retrieved from http://www.who.int/mediacentre/news/releases/2006/pr53/en/ (December 9, 2010)

World Health Organization. (2007). Country report and charts. Retrieved from http://www.who.int/mental_health/prevention/suicide/suiciderates/en/ (December 9, 2010)

Xing, X. Y., Tao, F. B., Wan, Y. H., Xing, C. Qi, X. Y., Hao, J. H., Su, P. Y., Pan, H. F., \& Huang, L. (2010). Family factors associated with suicide attempts among Chinese adolescent students: A national cross-sectional survey. Journal of Adolescent Health, 46, 592-599. http://dx.doi.org/10.1016/j.jadohealth.2009.12.006

Yip, P. S., Liu, K. Y., Lam, T. H., Stewart, S. M., Chen, E., \& Fan, S. (2004). Suicidality among high schools in Hong Kong, SAR. Suicide and Life-Threatening Behavior, 34, 284-297. http://dx.doi.org/10.1521/suli.34.3.284.42772 